\title{
The Effect of Sex and Education Level on Political Orientation
}

Georgia-May Thuesen

\begin{abstract}
The present paper examines the effects of gender and sex on political orientation. This topic is important because if a difference is found in gender and political orientation this could be an indication of one gender's needs not being met by political parties or the current government. The data that was used for the present paper was from the 2015 Alberta Survey. A sample size of 1,200 households was used and they were chosen by a two-stage selection process. Those over 18 of whom lived in a home that could be contacted via phone in Alberta were targeted for this survey. The findings were different from what was originally hypothesized. Gender was not found to play a role in political orientation. This finding differs from previous literature which had reported gender gaps. However, education level was found to have an effect on voting behavior.
\end{abstract}

Western political parties can generally be spilt into two categories: the left and the right. Those on the right are typically associated with conservative thought ("Right", 2010). Conservative thought is the idea that less government intervention is better for the economy, and conservatives actively advocate for little intervention in all economic and social aspects ("Conservatism", 2018; "Progressive Conservative Party of Canada", 2018). Left-wing parties are in favor of government intervention. They believe that social welfare is the of upmost importance ("Left", 2009), and favor the interests of the working people rather than the elites of

\footnotetext{
Vol. 4(1) | DOI: https://doi.org/10.31542/muse.v4i1.403 MacEwan University Student eJournal

(C) 2020 under CC BY-NC | ISSN 2369-56171
} 


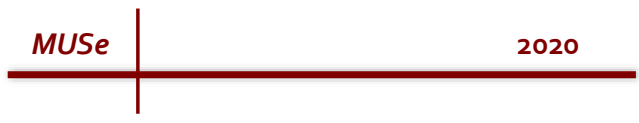

society ("Left", 2009). The majority of Albertans have traditionally been known to support the Progressive Conservatives (PC), a rightwing party, and voted them in for forty-four consecutive years, up until the 2015 election (Shirvastava \& Stefanick, 2015, p.3).

The two prominent left-wing parties found in Alberta are the New Democratic Party (NDP) and the Liberal Party of Canada. However, since the discovery of oil in Alberta in 1947 (Harrison, 2015, p.75), they had not seen any significant political support up until 1979. In 1979 the province of Alberta began to see a significant fall in oil prices (p. 78). During this period, the NDP and the Liberals saw an increase in seats. However, it wasn't until the 2015 election that the NDP gained enough support to break the overwhelming support for the PC Party (Shirvastava \& Stefanick, 2015, p.3).

For over forty years the PC party had been able to keep their political support strong by keeping taxes low, while still offering well-funded services, such as, health care, education, and other social services (Shirvastava \& Stefanick, 2015, p.3; Harrison, 2015, p.81). They managed this by funding social programs with the royalties they earned from oil (Harrison, 2015, p.81). Harrison (2015) discusses further that because of this reliance on the petroleum industry Alberta became captive to oil companies, with few options to fund the increasing rates needed for Alberta economic expansion (p.81). Combined with a rising public awareness of climate change (Davidson \& Haan, 2012, p.218), and Premier Alisson Redford's personal scandals (Harrison, 2015, p.84), the PC party saw their Progressive base becoming increasingly alienated (p.84). These turbulent times for the PC party lead to an increased amount of criticism from their own party members, and from the opposing left (p.85). This allowed for the right conditions for the NDP to gain political power in May of 2015 (p.85).

Most Albertans find themselves dependent on Alberta's petroleum industry and for many years, trusted the PC party to protect their interests (Shirvastava \& Stefanick, 2015, p.3). However, when faced with economic troubles (Harrison, 2015, p.84), changing beliefs in climate change (Davidson \& Haan, 2012, 
p.218), and declining spending on social services, it appears that many Albertans were willing to make a change in their voting behavior. If gender and education level is found to have an effect on an individual's voting behavior, this could be a result of those individuals needs not being met. Government policy makers could use this research to better understand the needs and concerns of their citizens. The present paper will examine the effect of education level and gender on the results of the 2015 election in Alberta.

\section{Literature Review}

Inglehart and Norris (2000) note a shift in political orientation among women during the 1980s (p.446). This article looked at data from variety of countries, including but not limited to, Canada, United States, and Sweden (Inglehart and Norris, 2000, p.449); to obtain a global theory on political orientation. In this article the developmental theory was used to describe the shift in political orientation among women. They explain this gender gap as a result of structural and situational difference in the individual's life. These differences could be in education, religion, and laborforce participation (Inglehart and Norris, 2000, p.446; Abenschon \& Steinmetz, 2014, p.340). In this article the change in gender voting patterns is attributed to the changes in gender roles. As gender roles transform, women gain more ability to partake in the work force and educational opportunities. These changes are expected to lead to changes in voting behavior (Inglehart \& Norris, 2000, p.446; Abenschon \& Steinmetz, 2014, p.339). They hypothesized that women who partake in education will become more inclined to vote liberal. Their results varied a bit because of cultural influences, however in general, they saw that women have become more politically left leaning than their male counterparts (Inglehart \& Norris, 2000, p.458; Gidengil, Everitt, Blais, Fournier, \& Nevitte, 2006, p.6).

Another study used data from nine Canadian elections from the years 1965 to 1997 (Erickson \& O'Neill, 2002, p.76). In 1970 they began to see gender differences emerge in political orientation (Erickson \& O'Neill, 2002, p.377). Women seemed to become somewhat less supportive of conservative parties. However, it was 


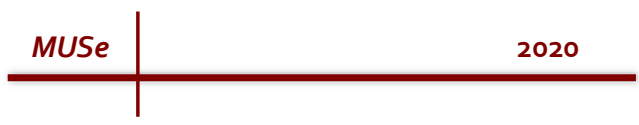

not until 1997 that they saw a significant increase in support for NDP by women. In 1997, women in general were found to be less likely to vote for any right-wing political party (Erickson \& O'Neill, 2002, p.379). They found that Canadian men in general had degrees regardless of who they voted for. However, it was found that the Canadian women who reported casting an NDP vote were more likely to have a bachelor's degree than other women (Erickson \& O'Neill, 2002, p.386; Gidengil et al., 2016, p.11). This supports Inglehart and Norris's findings that women with higher education tend to lean more to the left than other women.

Abendschön and Steinmetz (2014) hypothesized that women vote more left than men in countries with high female tertiary graduates (p.338). They reported that higher education was associated increased economic and political autonomy (Abendschön and Steinmetz, 2014, p.320). This study found that a large share of females, of whom were tertiary graduates, were more inclined to vote left than other individuals. Overall their study indicated that countries that have high gender empowerment saw an increase in females voting for the left (Abendschön \& Steinmetz, 2014, p.338; Gidengil et al., 2016, p.11). They suggest that future research should focus on specific gender preferences and that there should be more country specific studies in order to better identify social context factors (Abendschön and Steinmetz, 2014, p.341).

One study examined the political affiliation of Canadian university professors using a national survey that was conducted in 2000 (Nakhaie \&Adam, 2008, p. 873). It was observed that Canadian universities are primarily left leaning, although not fully (Nakhaie \&Adam, 2008, p.885). Those associated with the liberal arts were more likely to vote NDP than they were to vote Liberal (Nakhaie \&Adam, 2008, p.886). Overall, Canadian professors are described as being more left centrist in their voting behavior (Nakhaie \&Adam, 2008, p.893). It was found that more left leaning the individual was, the more likely they were to vote NDP (Nakhaie \&Adam, 2008, p.891). A study was conducted to examine how U.S. students and their relative's attitudes towards feminism differed. In this study they examined political orientation and education, as 
well as other variables (Bettencourt, Vacha-Haas, Byrne, 2011, p.863). In this study they observed that U.S. college students were more liberal in their political orientation than others in their family (p.871).

The research hypothesis is that education and gender will have an effect on an individual's political education. It is expected that the higher level of education an individual attains, the more likely they will be left leaning in their politics. It is also predicted that women will be more likely than men to vote NDP. The number of males who voted NDP will be compared with the number of women who voted NDP. Those with degrees will be compared with those who have only obtained a high school diploma. The percentage of men and women who have obtained bachelor's degrees will also be examined.

\section{Methods}

The data set used was the Alberta Survey. The sampling design was conducted with a two-stage selection process. The first selection was based on the selection of a household and the second was a selection of a respondent in the household. The survey was conducted with a sample size of 1,200 households. The targeted population were those over the age of 18 who live in a home that can be contacted via phone in Alberta. The sample was broken up into 400 respondents from the Edmonton Metropolitan area, 400 from those in the Calgary Metropolitan area, and 400 from the remainder of the province of Alberta. Random-digit dialing was used to ensure that households that do not have their number listed in a directory still have a chance of being contacted. This sampling approach method is ideal as it allows for the ability to clarify instructions and questions with the respondent. It also increases the likelihood that the respondent will answer sensitive questions (Symbaluk, 2014, p.166).

The administrations of the 2015 Alberta Survey were done with a 30-station CATI system. With this system, the interviewer sits in front of the computer (Symbaluk, 2014, p.164). The computer presents the questions in text on the screen; this allows for the interviewer to ask the questions over telephone, and then immediately enter the responses into a computer. A headset is 


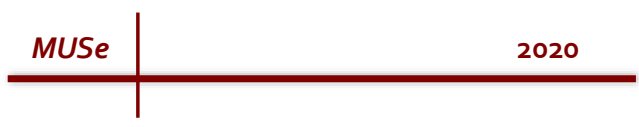

used so that they can record the answers (Symbaluk, 2014, p.164). The interviewers were allowed to make a total of six attempts before labeling the household as "no contact". If the household had a voicemail machine, the interviewer was to leave a scripted message; this was only to be done once. Upon contact with the respondent, the interviewer was required to inform the respondent that participation was voluntary, assure them of confidentiality, and declare that they could end the interviewing process at any point.

The independent variables of interest were education and sex. The level of measurement for education was ordinal. The survey question was "What is your highest level of education (this includes incomplete and complete)?". The following are the variables listed with their assigned value: $1=$ no schooling; elementary: 2 = incomplete and $3=$ complete; junior high: $4=$ incomplete and $5=$ complete; college/technical institute/trade: $8=$ incomplete and $9=$ complete; and university: $10=$ incomplete, 11 = diploma/certificate, 12 = bachelor's degree, 13 = professional degree, $14=$ master's degree, and $15=$ doctorate. This measure is valid as it is measured nominally. A Nominal scale of measurement is appropriate for this type of question (Symbaluk, 2014, p.82). Therefore, it can be assumed that this question has face validity, as it appears to be a good measure of the concept being examined (Symbaluk, 2014, p.91). The mode is the most frequently occurring value in a set of data (Lavrakas, 2008, para.1). Approximately $24.7 \%$ of the population $(n=1216)$ had completed college, technical institution, or trade.

The second independent variable of interest was sex. The level of measurement for sex was nominal. Nominal measurements are ideal for gender (Symbaluk, 2014, p.82). There was no specific question. The interviewer was to record the gender based on the respondent's voice, and only ask what the gender of the respondent was if they were not sure by the sound of the respondent's voice. The variables listed were $1=$ Male and $2=$ Female. This measure has face validity because the nominal measure is the most appropriate measure for measuring sex (Symbaluk, 2014, p.91). The mode is the most frequently occurring 
value in a set of data (Lavrakas, 2008, para.1). Approximately $50.3 \%$ of the population $(n=1216)$ were male.

The dependent variable that was examined was political orientation. The level of measurement for political orientation was nominal (Symbaluk, 2014, p.82). The survey question used was "How did you vote in the last provincial election which was held on May 5, 2015?". The following variables were listed with their assigned value were 1=Alberta First Party, 2= Alberta Liberal Party, 3= Alberta New Democratic party, $4=$ Alberta Party, $5=$ Alberta Socialist Credit Party, $6=$ Communist Party, $7=$ Green party of Alberta, $8=$ Progressive Conservative Association of Alberta, $9=$ Wildrose Party, 10 = Other (specify), 11 = Not eligible, 12 = Eligible to vote but did not vote, $13=$ Don't know/undecided, and $14=$ No response/refused. This article uses a nominal measure (Symbaluk, 2014, p.82). This type of measure is the most appropriate measure for measuring political orientation. As a result, it can be said that this measure possesses face validity (Symbaluk, 2014, p.91). The mode is the most frequently occurring value in a set of data (Lavrakas, 2008, para.1). Approximately $42.9 \%$ of the population $(n=1216)$ voted NDP.

\section{Findings}

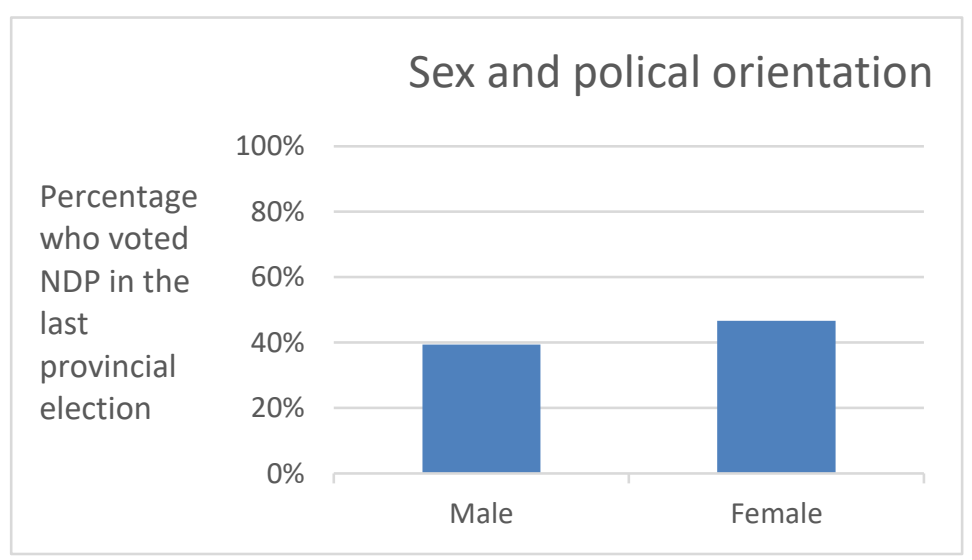




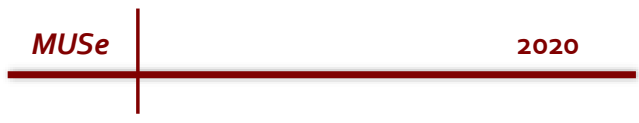

Approximately $39.4 \%$ of males said they voted for NDP in the last provincial election. While approximately $46.4 \%$ of females said they voted for NDP in the last provincial election the relationship was not found to be significant $(p>.05)$.

\section{Sex and education}

$100 \%$

Percentage 80\%

who

attained a

bachelors

$60 \%$

degree

$40 \%$
$20 \%$
$0 \%$

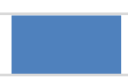

Male

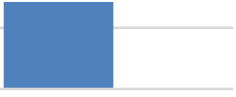

Female

Approximately $19.5 \%$ of males reported that they had attained a bachelor's degree, while approximately $28.4 \%$ females reported having attained a bachelor's degree. The relationship was found to be significant $(p<.05)$.

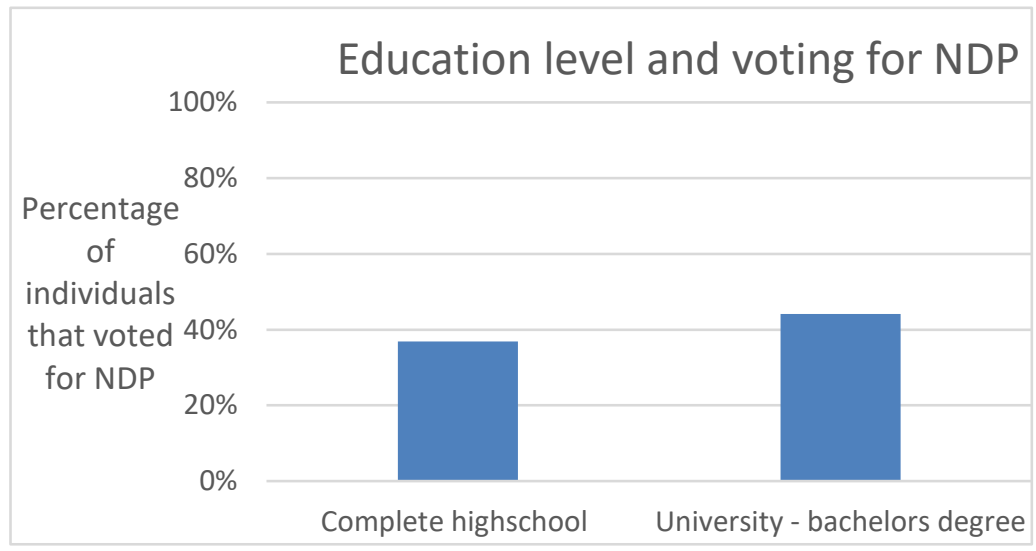


Approximately $36.9 \%$ of those who finished high school reported voting for NDP. Approximately $44.1 \%$ of those who obtained a bachelor's degree reported voting NDP. The relationship was found to be significant $(p<.05)$.

\section{Discussion and Conclusion}

Gender was hypothesized to have an effect on political orientation. However, this was not found in the present data. Unlike previous research, gender was not found to have an effect on the party the individual voted for. Although more women did vote for the NDP than men, the relationship was not found statistically significant. This finding differs from previous research which found that women were more left leaning (Inglehart \& Norris, 2000, p.458; Abendschön \& Steinmetz, 2014, p.338). This could be accounted for by protest votes. The male population that traditionally voted Progressive Conservative, may have voted in protest for the NDP, since many before the election found themselves becoming increasingly alienated from the PC Party (Harrison, 2015, p.84). The validity of this statement could be further explored in future research.

Education level was found to have an effect on voting behavior. Those who attended university and attained a bachelor's degree were more likely to vote NDP than those who only obtained a high school diploma. Previous research found that women who got a bachelor's degree were more likely to vote left (Abendschön \& Steinmetz, 2014, p.338). Another study looking at Canadian university professors also reported that those individuals with higher education were more likely to vote left (Nakhanie \& Adams, 2008, p.885). Davidson and Haan (2011) state that those who vote Conservative are significantly less likely to believe in climate change (p.229). So, considering that those with higher education are typically left leaning, it could be thought that they possess more knowledge on climate change issues compared to those with less education. The possible link between education and climate change beliefs could be further explored in future research.

Overall the results were different from what was hypothesized as gender did not appear to play an important role in political orientation. This is surprising as previous literature reported a 


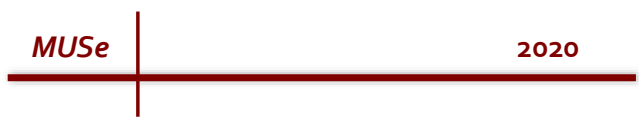

gender gap. This finding is new from the previous research and for this reason should be examined further. One common theory was the traditional gender gap theory. This is the idea that the gender differentiation in political orientation can be explained by differences in education, religion, and labour force participation (Inglehart \& Norris, 2000, p.446). It could be argued that as time passes men and women become more similar in these aspects and that is why there is no association between gender and political orientation (Trevor, 1999, p.63). Alberta has a unique economic history may also play a strong role in this finding. Future research would benefit from researching the role a petroleum-based economy plays in gender and political orientation, and how that differs from a more diversified economy.

Telephones surveys are a good survey method as they are cost effective, allow the interviewer to be able to clarify any instructions and questions, and respondents are more likely to respond to sensitive questions (Symbaluk, 2014, p.166). However, there are some disadvantages. It is more difficult for the interviewer to prove credibility and gain trust over the phone with respondents, unlisted numbers may not be answered by potential respondents, and this method also does not account for those individuals without phones (Symbaluk, 2014, p.165). Future research using face to face interviews would be advantageous because you can reach populations that may have not been reachable over the phone (Symbaluk, 2014, p.166). For this particular research question, it would have been more advantageous to use a different survey question for education. Using a survey question that measures the total number of years of schooling a respondent has done would give a better qualitative measurement for whether there is more or less of this area of interest (Symbaluk, 2014, p.166). This paper looked exclusively at one set of data. Future research would benefit from looking at multiple data sets to gain a more universal argument about how gender and education play a role in voting pattern. 


\section{References}

Abendschön, S., \& Steinmetz, S. (2014). The Gender Gap in Voting Revisited: Women's Party Preferences in a European Context. Social Politics: International Studies In Gender, State \& Society, 21(2), 315-344. doi:10.1093/sp/jxu009 Bettencourt, K. E. F., Vacha-Haase, T., \& Byrne, Z. S. (2011). Older and younger adults' attitudes toward feminism: The influence of religiosity, political orientation, gender, education, and family. Sex Roles, 64(11-12), 863-

874. doi: 10.1007/s11199-011-9946-z

Conservatism. (2018). In Encyclopedia Britannica, Retrieved from https://www.britannica.com/topic/conservatism

Davidson, D. J., \& Haan, M. (2012). Gender, political ideology, and climate change beliefs in an extractive industry community. Population and Environment, 34(2), 217-234.

Erickson, L., \& O'Neill, B. (2002). The gender gap and the changing woman voter in Canada. International Political Science Review, 23(4), 373-392.

Gidengil, E., Everitt, J., Blais, A., Fournier, P., \& Nevitte, N. (2006, August). Gender and vote choice in the 2006 Canadian Election. In Annual Meeting of the American Political Science Association, Philadelphia, PA (p. 10).

Harrison, T. W. (2015). Petroleum, Politics, and the Limits of Left Progressivism in Alberta. Alberta Oil and the Decline of Democracy in Canada, 69-88.

Inglehart, R., \& Norris, P. (2000). The Developmental Theory of the Gender Gap: Women's and Men's Voting Behavior in Global Perspective.

International Political Science Review, 21(4), 441.

Left. (2009). In Encyclopedia Britannica, Retrieved from https://www.britannica.com/topic/left

Mode. (2008). In P. J. Lavrakas (Ed.), Encyclopedia of Survey

Research Methods (Vol. 1, p.475). Thousand Oaks, CA:

SAGE Publications. Retrieved from http://go.galegroup.com.ezproxy.macewan.ca/ps/i.do?id $=$ GALE $\% 7 C C X 3073300313 \& v=2.1 \& u=e d m o 87290 \& i t=r \& p$ 


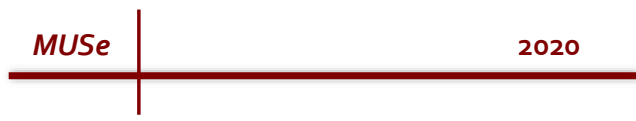

$=$ GVRL\&asid $=3 \mathrm{ddfd} 1018 \mathrm{~b} 8 \mathrm{f} 62 \mathrm{~b} 63 \mathrm{~d} 5034 \mathrm{bfc} 68768 \mathrm{ff}$

Nakhaie, M.R., \& Adam, B. D. (2008). Political Affiliation of

Canadian University Professors. Canadian Journal of

Sociology, 33(4), 873-897.

Progressive Conservative Party of Canada. (2018). In Encyclopedia

Britannica, Retrieved from

https://www.britannica.com/topic/Progressive-

Conservative-Party-of-Canada

Right. (2010). In Encyclopedia Britannica, Retrieved from

https://www.britannica.com/topic/right

Symbaluk, D. (2015). Research Methods: Exploring the Social

World. Toronto: McGraw-Hill.

Shrivastava, M., \& Stefanick, L. (2015). Framing the Debate on

Democracy and Governance in an Oil-exporting

Economy. Alberta Oil and the Decline of Democracy in

Canada.

Trevor, M. C. (1999). Political socialization, party identification, and the gender gap. Public Opinion Quarterly, 62-89

University of Alberta. (2015). 2015 Alberta Survey a Methodology

Report [PDF]. Retrieved from

https://learn.macewan.ca/bbcswebdav/pid-884616-dt-

content-rid 2331374_1/courses/

007256-01-2159-1-AS01-92034/2015ABSurveyA-

ClimateDialogueMethodologyReport.pd 